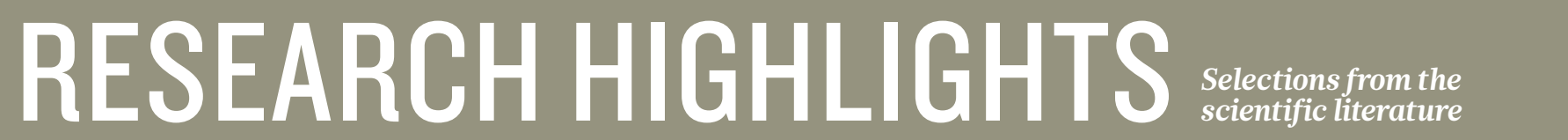

NEUROSCIENCE

\section{Cell transplants for pain}

Transplanting embryonic neurons into the mouse spinal cord seems to alleviate neuropathic pain - chronic pain that arises spontaneously or in response to the slightest touch due to peripheral nerve injury.

In this type of injury, signalling by spinal cord neurons that produce a neurotransmitter called GABA is reduced. João Bráz and his colleagues at the University of California, San Francisco, transplanted GABA-producing interneurons from the mouse embryonic forebrain into the spinal cords of adult mice with peripheral nerve injury. The transplanted cells integrated into the hosts' spinal cord circuitry and eliminated touchinduced hypersensitivity in mice with neuropathic pain, but had no effect in animals with inflammatory pain. Neuron 74, 663-675 (2012)

\section{BIOCHEMISTRY}

\section{Proteins designed} \section{to self-assemble}

Large protein complexes can be designed and created using smaller protein building blocks that self-assemble.

David Baker at the University of Washington, Seattle, and his team report a

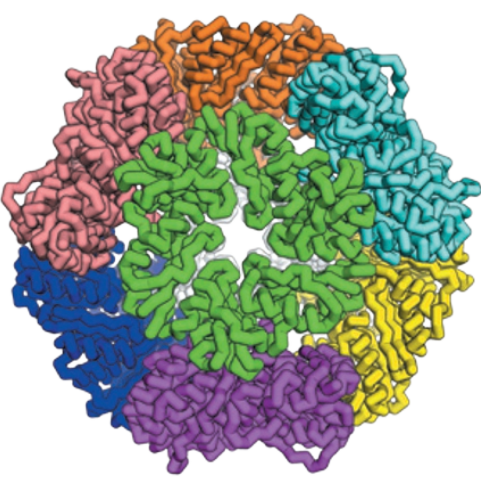

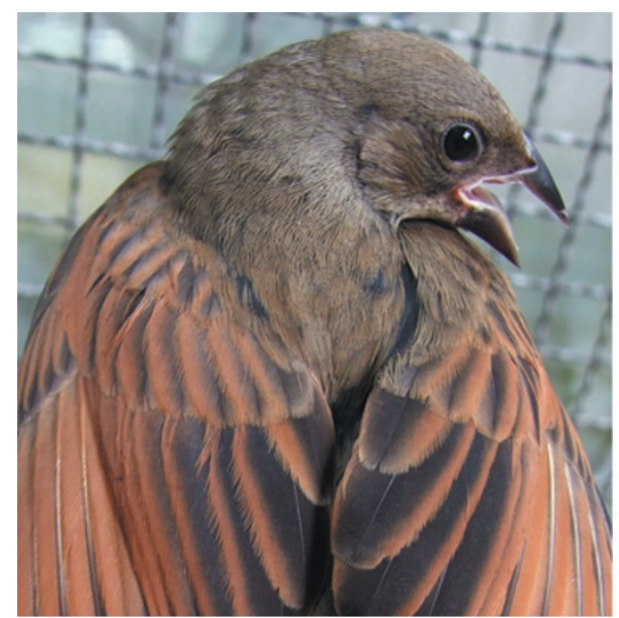

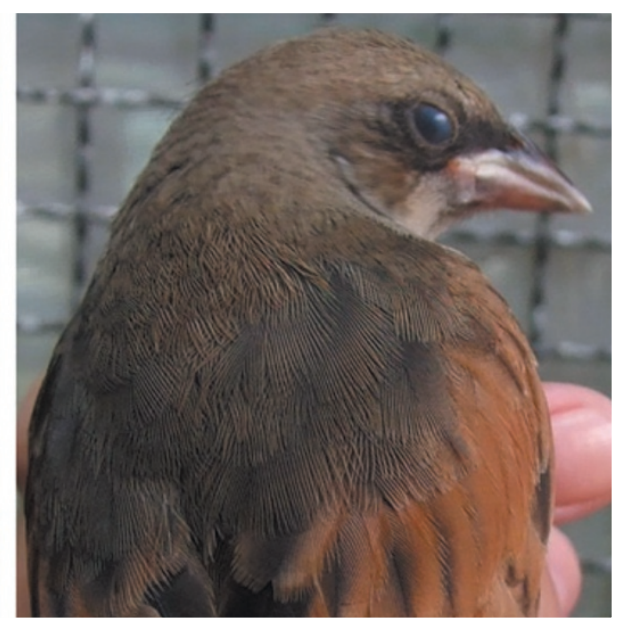

\section{EVOLUTION}

\section{Fledglings occupy nests, fool hosts}

Birds such as the cowbird that lay their eggs in the nests of other birds have evolved strategies to disguise their chicks and not just their eggs.

María De Mársico and her colleagues at the University of Buenos Aires observed eggs or hatchlings from the screaming cowbird (Molothrus rufoaxillaris; pictured left) or the shiny cowbird (Molothrus bonariensis) that were placed or laid in the nests of the baywing (Agelaioides badius; right), and measured the fledglings' survival rates. The researchers found that the baywing hosts rejected $83 \%$ of the shiny cowbird fledglings, but none of the screaming cowbirds. Analysis of the birds' plumage revealed that the differences in colour between screaming cowbird and baywing fledglings are likely to be indistinguishable to the avian eye. The begging calls of these species are also very similar, whereas the shiny cowbirds differ in their calls and appearance.

Proc. $R$. Soc. B http://dx.doi.org/10.1098/

rspb.2012.0612 (2012) method for producing such proteins. The authors simulate the docking of protein building blocks in desired architectures and then design amino-acid sequences for these blocks that result in lowenergy interfaces between the blocks, driving self-assembly. The researchers incorporate the genes that encode the designed blocks into the bacterium Escherichia coli, which produces the proteins that then spontaneously self-assemble into the target architectures. The team created two cage-like proteins: one consisting of 24 building blocks in a 13-nanometre-wide complex with octahedral symmetry (pictured) and another comprising 12 subunits with an 11-nanometre-wide tetrahedral symmetry. Science 336, 1171-1174 (2012)

\section{ANTHROPOLOGY}

\section{Rich milk for poor girls}

Poor mothers in northern

Kenya produce fattier milk for their daughters than for their sons, whereas those who are better off financially favour their sons over their daughters. The findings support a 1973 hypothesis that predicts that poor mothers will invest more resources in daughters, who stand a greater chance of increasing their status through marriage than do poor males. Conversely, mothers from wealthier families give more to their sons, who can pair with multiple females.

Masako Fujita at Michigan State University in East Lansing and her team assessed the fat content of milk from 83 mothers living in villages in which men can have multiple wives. The authors found that, when they controlled for factors such as age and dietary fat intake, mothers with less land and fewer livestock provided richer milk to their daughters than to their sons. Am. J. Phys. Anthropol. http:// dx.doi.org/10.1002/ajpa.22092 (2012) 